\title{
fedea
}

\section{Gender Gaps in Performance Pay: \\ New Evidence from Spain}

by

Sara de la Rica*

Juan J. Dolado*"

Raquel Vegas*

Documento de Trabajo 2013-14

November 2013

* Universidad del País Vasco, FEDEA \& IZA.

** Universidad Carlos III \& CEPR \& IZA.

*** FEDEA.

Los Documentos de Trabajo se distribuyen gratuitamente a las Universidades e Instituciones de Investigación que lo solicitan. No obstante están disponibles en texto completo a través de Internet: $h t t p: / / w w w$.fedea.es.

These Working Paper are distributed free of charge to University Department and other Research Centres. They are also available through Internet: http://www.fedea.es.

ISSN:1696-750 


\title{
Gender Gaps in Performance Pay: New Evidence from Spain *
}

\author{
Sara de la Rica*, Juan J. Dolado** \& Raquel Vegas***
}

(*) Universidad del País Vasco, FEDEA \& IZA

$\left.{ }^{* *}\right)$ Universidad Carlos III \& CEPR \& IZA

$(* * *)$ FEDEA

\begin{abstract}
This paper analyzes the gender gap in the performance-pay component of hourly wages received by workers in Spain using detailed information drawn from a large wage survey for 2006. Under the assumption that performance pay is determined in a more competitive fashion than the remaining wage components, there should be less room for gender discrimination. However, this is not what we find. After controlling for observable characteristics, non-random selection into performance-pay jobs and for segregation into different firms and occupations, the estimated adjusted gap in favour of male remains large (around $30 \log$ points). Further, there is evidence of a "glass ceiling" pattern throughout the distribution of performance pay. After examining alternative hypotheses that could rationalize these findings, we conjecture that employers' discrimination, possibly due to monopsonistic power, might be the one which is more consistent with the evidence.
\end{abstract}

JEL Classification: J31, J33, J42, J71.

Keywords: performance pay, gender gaps, selection bias, quantile regressions, glass-ceiling

\footnotetext{
*We are grateful to Ghazala Azmat, Manuel Bagues, Daniel Parent, Iliana Reggio and participants in several seminars for useful comments on preliminary versions of this paper. The first two authors gratefully acknowledge financial support from the Spanish Ministry of Education (ECO2009-10818; SEJ200763098), MCINN (Consolider- Ingenio2010) and Consejería de Educación de la Comunidad de Madrid (Excelecon project) .
}

Corresponding author: Sara de la Rica (ara.delarica@ehu.es). 


\section{Introduction}

In contrast to a vast literature which focuses on explaining differences in total pay received by male and female workers, there is only a sparse literature analyzing gaps in one particular portion of wages that is becoming increasingly relevant, namely, performance pay (henceforth PP). ${ }^{1}$ This component is particularly interesting because it could be considered as a better proxy of the conventional "wage equals marginal revenue product" textbook condition than other wage components (e.g.,the base wage) that often do not depend so closely on individual performance.

Following this intuitive reasoning, Lemieux et al. (2009) have analyzed the impact of performance pay (PP hereafter) on wage inequality in the US. Their basic hypothesis is that, through a widespread reduction in the cost of gathering and processing information, growing incidence of PP may have contributed to the increase in inequality, mainly at the top of the wage distribution. Indeed, their finding that PP accounts for $25 \%$ of male wage inequality between the late 1970s and early 1980s provides favourable support for this conjecture.

In this paper, we contribute to this line of research by making use of a dataset on the detailed breakdown of total wage compensation for workers in Spain into its different components. We re-examine Lemieux et al. 's (2009) hypothesis, but from a different angle. Specifically, our interest lies in analyzing gender gaps in the PP compensation received by these workers and interpreting the findings in terms of the implications of several theories about these gaps.

To our knowledge, there are only two clear forerunners to our paper in the economics literature. The first one is Chauvin \& Ash (1994) who use wage micro data drawn from a survey of business school graduates in the US to examine how the gender gap structure changes across different pay components. In contrast to our sample, which covers a large fraction of Spanish employees, theirs is a small one and cannot identify firm fixed effects, as we do here. The second one is Manning and Saidi (2010) which is the closest paper to ours. They use the two most recent waves of the Workplace Employee Relations Survey (WERS) in the UK (a matched employeremployee establishment-based survey) to focus on PP as an indicator of competition in the workplace. The idea is to check whether the finding in laboratory experiments that men and women exhibit different attitudes to competition can be mapped into real world (see, e.g., Gneezy et al., 2003, and Niederle and Vesterlund, 2007). Their main conclusions is that gender gaps in PP and even in work effort are modest, and therefore

\footnotetext{
1 Most papers in the literature on this topic have mainly dealt with analyzing the incentive effects of PP on productivity; see e.g., Dohmen and Falk (2009), Lazear (2000) and Lavy (2009), and the references therein. A gender perspective on this issue, related to the education system, can be found in Lavy (2011).
} 
that the ability of such theories to explain the gender pay gap is limited. Our results differ quite drastically from theirs: we find much larger gender differences in PP than in the remaining wage components. In this sense, since the UK and Spain have quite different regulations regarding labor market relations and collective bargaining, our results may shed light on the consequences on these regulations on the determination of PP by gender.

From a theoretical perspective, there are several alternative hypothesis which lead to different predictions about gender gaps not only in the magnitude of the PP component, but also in the incidence in PP jobs:

- If PP is determined in a more competitive fashion than other wage components, equally performing men and women should receive the same compensation in terms of this wage component. Hence, gender differences in PP should be smaller than in the other wage components that respond less to meritocracy. Moreover, if women perceive some forms of (taste and/or statistical) discrimination against them in non-PP jobs, then it is likely that they would seek intensively for PP jobs in order to ameliorate these disadvantages.

- The assumption of equally performing men and women may however be controversial. In effect, to the extent that effort at the marketplace may be negatively affected by housework, PP could also provide a clear channel through which women's greater involvement in housework hinders their returns in the labour market and therefore reduces lower their PP compensation relative to men 's. In other words, gender differences in effort at the workplace may still entail gender differences in PP even if this wage component is determined in a competitive setting.

- Another source of gender differences in PP is occupational segregation, which may arise due to alternative hypothesis stemming from either the worker's or the employer's sides. On the one hand, women might select themselves into non-PP jobs (e.g., most public sector jobs) because they anticipate that these positions are more compatible with their larger household responsibilities. In line with the so-called mommy track hypothesis (see Mincer and Polacheck, 1977), they may willingly opt for jobs entailing steadier and, possibly, lower pay in exchange for less penalties in case of career interruptions. As pointed out earlier, another reason why women may select themselves into non-PP jobs is that they dislike competing with men in highly competitive jobs, like those providing PP. On the other hand, occupational segregation may arise as a consequence of statistical discrimination from the employer's side: they might be more reluctant to place women in fast-track jobs, likely to involve PP, if they expect lower female work attachment even if they have the same skills as their male colleagues (see Lazear and Rosen, 1990). Moreover, anticipation by women of 
some sort of statistical discrimination may discourage them from applying to these jobs, leading to self-fulfilling equilibria (see Dolado et al., 2012). It is important to note that, under the occupational segregation hypothesis, irrespectively of its source, we would expect to observe a lower incidence of women in PP jobs relative to men. However, there is no reason why it should lead to large gender differences in the magnitude of PP when similarly skilled men and women working in the same or very similar jobs (same firm and occupation) are compared.

- Employers with some monopsonistic power may discriminate against women in the PP component. This may be the case if employers perceive women as having lower mobility or lacking alternative job offers, (see Booth et al, 2003 and Manning, 2003)

- Finally, gender differences in preferences with regards to the pecuniary nature of PP compensation may lead to different bargaining outcomes between employers and employees with respect to this component. If women prefer other nonpecuniary benefits, such as work flexibility, this might end up in lower PP compensation even among men and women employed in the same jobs.

In view of these considerations, this paper tries to dig deeper into the extent and determinants of gender gaps in PP in Spain with the goal of identifying which of the above-mentioned theories fits better with our findings. Our data comes from the 2006 wave of the Spanish Earnings Structure Survey which contains detailed micro-data information on the various components of the wage, such as the base wage, overtime pay and other wage complements. In comparison to the longitudinal dataset used by Manning and Saidi (2010), our cross-sectional dataset suffers from the clear drawback of not being able to control for workers' fixed effects, as they do. In exchange, we have information on how PP is disaggregated by particular occupations within plants/firms, while they only have information on PP within firms. As will become clear below, our more disaggregated information becomes key in disentangling among the alternative theories of the gender gap in PP. Further, instead of concentrating exclusively on the PP gender gap at the mean, as these authors do, we also analyze how the gaps evolve throughout the PP distribution given that the previous theories have different implications about this issue.

The rest of the paper is structured as follows. Section 2 describes the dataset and provides some basic descriptive statistics regarding the whole sample, the distribution and extent of PP, and the differences between the observable characteristics of workers receiving and not receiving PP. In Section 3 we test whether PP is set in a more 
competitive way than the other wage components. Section 4 analyzes which of the above-mentioned theories fits better with our empirical finding on the adjusted gaps in PP, once differences in personal and job characteristics across genders and nonrandom selection of workers into PP jobs are accounted for. Finally, Section 5 concludes.

\section{Data and descriptive statistics}

The data source is the third (2006) wave of the Spanish Earnings Structure Survey (Encuesta de Estructura Salarial or ESS 06 in short). ${ }^{2}$ The survey is based on twostage random samples of workers from establishments in the manufacturing, construction and service industries including firms with less than 10 employees. First, establishments are randomly selected from the Social Security General Register of Payments records, which are stratified by region and establishment size. In a second stage, samples of workers from each of the selected establishments are again randomly drawn. Overall, not only sample sizes are much larger than those provided by any other Spanish wage surveys but also, aside from wage compensation, EES collects individual information on workers' demographics (such as age and educational attainment) and job characteristics (including industry, occupation, contract type, type of collective bargaining, establishment's export activity, establishment size, and region).

The main advantages of this database is that it includes a module where employers provide detailed information on the breakdown of the total annual wage compensation paid to the workers in their firms into fixed and variable components. Besides reporting total monthly gross wages and effective (weekly) working hours, EES 06 does provide information both on the ordinary (base wage and other complements due to shifts, tenure, job risks, etc.) and non-ordinary components of annual gross earnings. Regarding the latter category, the ESS 06 distinguishes between two different types of payments:

- Fixed Annual Non-ordinary Payments. This payment "basically corresponds to extraordinary compensations at Christmas and summer vacations (in Spanish, known as pagas por navidad y verano) ${ }^{3}$, the standard rates for overtime work and participation in firms' ordinary and extraordinary profits". It is specifically stated that their amount is known in advance by the employee, typically established at the collective

\footnotetext{
2 The previous waves correspond to 1995 and 2002.

3 This implies that the fixed part of the total annual gross wage is distributed into 12 ordinary installments and 2 extraordinary ones in June and December. This tradition dates back to the Francoist industrial relations during the dictatorship period in Spain.
} 
bargaining level, and that they do not depend on either workers' or firms' performance.

- Variable Annual Non-ordinary Payments. In contrast to the first category, these are payments related to workers' individual performance as well as to firm performance. The amount is not known in advance and it is determined as a function of production objectives, quality and quantity of sales, benefits, etc. whose amount is not established a priori. Payments are not received periodically, and the variable lumps together bonuses, compensations and piece rates.

Given this breakdown of total wage compensation, the PP component in the sequel will correspond to the Variable Annual Non-ordinary Payments. Available information on weekly hours of work is used to compute hourly PP. This avoids potential differences in this wage component due to differences in hours worked. In the same vein, the nonPP component will be identified as the sum of the ordinary wage and the Fixed Annual Non-ordinary Payments, also in hourly terms.

An important issue to consider is that the variable Annual Non-ordinary Payments not only contains PP compensation but also profit sharing schemes, so that its interpretation exclusively in terms of workers' merit pay may be subject to a nonnegligible measurement error. This must be taken into account in the descriptive analysis of PP. However, to the extent that most of our analysis focuses on adjusted gender gaps in PP for men and women working in the same firm and occupation (18 occupational categories), differences in profit-sharing compensation are likely to be small. As a result, there is some justification for interpreting the chosen definition of the PP variable as mostly reflecting merit pay.

\subsection{Description of the dataset}

Our sample consists of full-time workers aged 18-65 for whom the interview month (October) is an ordinary period regarding their labour status. Table 1 displays the weighted descriptive statistics for the male and female samples. The sample size is 195,153 and contains a total of 129,930 males $(66.6 \%)$ and 65,233 females $(33.4 \%)$ covering almost 18,000 establishments.

Inspection of workers' demographic characteristics reveals the following three salient facts: (i) women have on average significantly larger educational attainment than men - e.g., the percentage of female workers with a university degree (32\%) almost doubles men's (18\%) whereas the fraction of women with at most primary education is 10 pp. smaller (18\% vs. $28 \%)$; (ii) women are about two years younger 
than men (from interpolation of the mid-points of the different age brackets), (iii) female job tenure is about 1.5 years shorter than males' tenure. As regards firms' characteristics, we find that women work in larger establishments (> 200 employees) than men (a 9 pp. higher share), and that they enjoy a lower coverage by bargaining agreements at the firm level (3 pp. less).

Regarding total gross hourly wages, the raw gender gap in favour of men is about $21 \log$ points while, for the subsample of PP workers, it goes up to $25.6 \log$ points. Among the latter, the most interesting finding is that the gender gap in the PP component rises to $46 \log$ points, namely about twice the gap in the fixed wage component (23.4 log points). This gap is strikingly larger than the one reported by Manning and Saidi (2010) in their study for the UK, which makes it therefore interesting to explore the reasons for such contrasting findings. Finally, female incidence in PP jobs is smaller than male's incidence (17.7\% against $19.4 \%)$.

\subsection{Characterizing PP Compensation}

Table 2a compares the sample characteristics of workers and firms in the PP and non-PP samples distinguishing by gender. ${ }^{4}$ The main finding is that workers receiving PP are more skilled than those not receiving PP (40\% of women and $28 \%$ of men in the PP sample have a college degree against $29 \%$ and $15 \%$ in the non-PP sample). Likewise, they are older (about a 10 pp. larger share in the 41-50 age brackets), have longer tenure (about 2.5 years longer for women and 4 years for men), enjoy a higher rate of permanent contracts and work in larger establishments (typically less subject to centralized bargaining levels).

Table $2 b$, in turn, presents the incidence of PP jobs by industry and occupation. Regarding industries, Financial Intermediation (60\%) and Education (9\%) are the sectors where PP is most and least prevalent, respectively. As for occupations, the results confirm that PP incidence is much higher for the high-wage categories: $50 \%$ for Managers and 30\% for Professionals and Technicians.

Finally, Table 2c reports the share of female workers receiving PP throughout the distribution of this component of the wage (proportion of women among workers receiving PP in each decile) which can be compared to the average share of women receiving PP in our sample $(17.7 \%)$. There is a clear sharp decline in this proportion, as we move upwards in the PP distribution - from $41 \%$ at the bottom to $16 \%$ at the top.

\footnotetext{
4 The non-PP sample includes those workers who do not report any positive variable annual non-ordinary payments. Some of these workers may have the right to receive PP compensation in their labour contracts but, for different reasons, they did not get it. It is not possible to disentangle between these two types of workers within the sample of non-PP workers. Given that the focus of the paper is not PP per se, but rather gender gaps in PP, our implicit assumption is that the distribution of this potential measurement error is similar among men and women and hence that it does not affect our results in a significant way.
} 


\subsection{Raw gender gaps in PP}

We next analyze the relative magnitude of PP out of total wages and study more closely the size of the gender gap in this wage component. The first four columns in Table 3 present the total hourly wage compensation for workers with PP schemes (expressed in $€$ ) across genders and the corresponding shares of total wages accounted by the PP component.

As can be inspected, workers receiving PP earn much more on average than workers who do not receive it (about 64\% and 50\% higher wages for men and women, respectively) in line with the evidence offered in Table 2a about their higher skills and longer job tenure. However, the share of the PP component in the total wage is rather low (on average 7\% for women and 9\% for men), though it increases throughout the wage distribution, reaching $22 \%$ (men) and 17\% (women) at the $90^{\text {th }}$ percentile (P90th). As explained in de la Rica et al. (2010), taking both features together, the contribution of the gap in PP to the overall gender gap for the whole sample of workers is small: about $7 \%$ on average and $12 \%$ at the upper part of the wage distribution. When considering exclusively the PP sample, these contributions are more relevant, reaching $18 \%$ on average and almost $25 \%$ at the top of the distribution.

In sum, two main findings can be drawn from this preliminary evidence: (I) the gender gap in the (hourly) PP component is much larger than in the total hourly wage compensation, particularly at the top of the wage distribution, and (II) PP makes a dent at higher wages in line with the previous evidence which reveals that workers who receive PP exhibit higher observable skills.

The result that the gender gap in PP is much larger than in total wages, a feature which remains even within firms and/or occupations (see below), constrast shaply with the results reported by Manning and Saidi (2010) for the UK, where the opposite happens. One plausible rationalization of this different patterns could rely on the evidence provided by Dolado et al. (1997) pointing out that employers in Spain improve high-skill workers' pay above compressed bargained wages aggred with unions. They do so through formal and informal agreements which are likely to involve PP arrangements, and which are paid on a more discretionary basis. Insofar as unions compress the wage distribution and base wages respond more to occupational categories and tenure than to individual characteristics, it is likely that the raw non-PP gender gap would be quite smaller than the raw PP gap. This sharply contrasts to the situation in the UK, where unions'coverage is quite lower. This is confirmed by the fact that the standard deviation of the (logged) fixed component of total hourly wages in Spain (0.61 and 0.60 for men and women, respectively) is less than one-half of the standard deviation of the (logged) PP component (1.41 and 1.34, respectively). 
However, before proceding to examine potential explanations for the PP gender gap in Spain several preliminary steps must be taken. First, in line with Lemieux et al.'s (2009), we need to show that PP tends to respond more to workers' characteristics than the other components of the hourly wage. Next, we also need to check whether the above-mentioned patterns of the raw gap in PP remain once we adjust for differences in observed individual and job characteristics across genders, correct for non-random selection into the PP sample of workers and, moreover, compare men and women working in the same firm and occupation. In other words, it is only under the competitive labor market paradigm and under similar observable characteristics that the documented PP gap can be described as being "strikingly large", as we did before. The next two sections are devoted to address these issues in detail.

\section{Is PP determined in a competitive fashion?}

We first analyze in this section whether the PP component is "more attached to the worker" whereas the non-PP component of the wage is more "attached to the job". The basic insight is that, if PP responds mainly to workers' productivity, then human capital variables - basically age, education and job tenure- should have higher market returns in this kind of jobs than in other jobs not involving PP. Conversely, returns to job characteristics- such as firm size, sector, and tenure in the firm- should receive a higher market reward in term of the non-PP component.

To address this issue, Table 4 reports standard mincerian (logged) total hourly wage regressions estimated by OLS where the returns (estimated coefficients) to job and human capital variables are displayed separately in the first two columns for PP and non-PP samples, respectively. The last column, in turn, shows the results from a pooled regression where interactions of human capital and job characteristics with an indicator of receiving PP are added to test for statistically significant differences between returns in the two samples. Thus, denoting the hourly wage of worker $i$ in firm $j$ as $W_{i j}$, individual and job characteristics as $X_{i}$ and $X_{j}$, respectively, and an indicator $(1 / 0)$ for receiving PP as $D_{i}$, the estimated model is:

$$
\ln W_{i j}=\beta_{0}+\beta_{1} D_{i}+X_{i} \beta_{2}+X_{j} \beta_{3}+D_{i} X_{i} \phi_{1}+D_{i} X_{j} \phi_{2}+\varepsilon_{i j}
$$

where we expect $\phi_{1}>0$ and $\phi_{2}<0$.

Our results are similar to those found by Lemieux et al. (2009) for the US. For example, the returns to college and secondary education are $41 \%$ (0.304 vs. 0.215$)$ and $60 \%$ (0.09 vs. 0.06) larger, respectively, in the PP sample than in the non-PP sample. Likewise, the returns to age, as a proxy for potential experience and, to a lesser extent, job tenure follow the same pattern. By contrast, the returns to firm size and other job 
characteristics are significantly higher in the non-PP sample as is also the case for estimated coefficients on industry and occupational dummies, not reported here to save space. Overall, this evidence supports the view that PP is closer to worker's productivity than the other wage components. Yet, the fact that estimated returns on firm's characteristics are, in general, statistically significant points out that workers tend to be categorized by firms into jobs, albeit less so in the PP sample.

\section{Adjusted gender gaps in PP}

The next step is to compute the gaps in PP adjusting for differences in observed individual and job characteristics. However, the fact that slightly less than one-fifth of workers in the whole sample receive PP schemes and that these workers present different personal and job characteristics than non-PP workers, make us consider that non-random selection of workers into the PP sample may be a relevant issue to address. This is particularly important if the selection process into PP is not exactly the same for males and females, since ignoring gender differences in selection may lead to biased estimates of the adjusted PP gap.

\subsection{Selectivity issues}

Finding an adequate instrumental to address the potential selectivity bias is difficult given that our dataset lacks information on family issues, such as civil status or number/age of children, which are the traditional instruments used in this context. Instead, we use the availability of wage bargaining at the firm level (Firm Agreement) as the identifying variable in the participation equation. For given individual and other job characteristics, workers who end up in jobs with this type of decentralized wage agreement are more likely to receive PP than those in jobs where wages are set at a more centralized bargaining level (sectoral/provincial or nationwide). In the latter jobs, unions play a prominent role in determining wages and often limit the use of PP schemes.

The choice of this indicator as an instrument may be critisized on the grounds that it clearly affects total wages. Yet, we cannot think of any strong argument about why it should affect the magnitude of the PP component for the sample of PP recipients (e.g, its estimated coefficient is insignificant in column (1) of Table 4). This makes us to somewhat trust the validity of this exclusion restriction despite the fact that that there are not strong conceptual arguments in its favour. Further, the results do not differ qualitatively from those obtained when we omit this exclusion restriction and therefore rely exclusively on non-linearities to achieve identification. At any rate, we present estimates with and without controlling for sample selection. Given that PP 
recipients exhibit higher observable skills than the rest, non-controlling for sample selection (OLS estimates) should lead to downward biased estimates of the actual gaps which must be taken into consideration when interpreting the results.

\subsection{Gender Gaps in Participation in PP schemes}

Table 5 presents the results of estimating a probit model to explain participation in the PP sample ( $\mathrm{PP}=1$, non- $\mathrm{PP}=0)$. This model will be later used to compute the inverse Mills ratio in a conventional two-stage Heckit approach to control for selection in the estimation of (logged) hourly PP mincerian regressions. In the first column of Table 5 we present the estimates of the coefficients in the probit using the standard explanatory variables, where a Female indicator captures gender differences in the probability of receiving PP compensation. As can be observed, women have a lower probability of getting PP than equally able men working in the same occupations. Notice that this does not contradict our previous finding about rather similar participation rates in the PP sample since now we are comparing men and women with the same observable characteristics whereas earlier the comparison was made across all workers. The remaining estimates are in line with the evidence presented in Table 2a: higher educational attainment, longer tenure and belonging to the 31-50 age bracket also raise this probability.

\subsection{Adjusted Gender Gaps in PP within firms and occupations}

Next, we estimate gender gaps in PP adjusting for differences in observed characteristics of male and female workers in the PP sample. Furthermore, as stated below, we estimate these gaps in three different setups: within firms, within occupations and within firms and occupation. More speciallally, we use the specification of a mincerian log wage equation for the restricted sample of PP workers with a Female intercept and equal returns to individual and job characteristics across genders. We compare the estimated coefficient on the Female indicator in a regression (augmented by the inverse Mills ratio obtained from the participation equation reported in the second column of Table 5) under four different specifications: (i) a pooled regression $(P)$, (ii) within- occupations $(W O),{ }^{5}$ (iii) within-firms $(W F)$, and (iv) within-firms \& occupations (WFO).

\footnotetext{
${ }^{5}$ We use the most disaggregated occupational classification available for our dataset, namely, 18 occupational categories
} 
Table 6 reports the estimates obtained under these alternative specifications where the OLS results (without selection correction) are also included in the first column for comparative purposes. The following findings stand out:

- First, the adjusted average gender gap in the OLS pooled specification is about 41 log points against a raw gap of 46 log points.

- Secondly, once we control for selection bias in such specification, the gap increases slightly to $45 \log$ points. The fact that this gap is larger than the OLS gap is explained by the highly significant positive sign on the coefficient of Heckman's lambda which reflects strongly positive selection of workers receiving PP. Since women have higher educational attainment than men in our sample, despite having lower tenure, this leads to a larger gap when selection is taken into account.

- Thirdly, again controlling for selection biases, the estimate of the gap in the within-firm specification (34 log points) is quite smaller than the corresponding estimate in the within-occupation specification (43 log-points) which, in turn, is quite close to the gap estimated in the pooled specification (41 log points).

- Finally, the gap in the joint within-firm and occupation (29 log-points) is slightly lower than the gap in the within-firm and within-occupation model.

\section{[Table 6 about here]}

\section{Quantile regressions}

Further evidence on gender gaps in PP can be obtained from a comparison of their patterns throughout the distribution of this component.

To do so, we use quantile regressions (QR) accounting for selectivity corrections under the within-firm \& occupation specification. Following Buchinsky's (1998) approach, the selectivity correction for workers receiving PP is based on a two-stage approach. First, a two-term series expansion of the inverse of the Mills ratio in Table 5 is used to obtain an estimate of a latent index that approximates the unknown quantile functions of the truncated bivariate distribution for the error terms in the wage and participation equations. Then, the covariance matrix for the two-stage QR and the selectivity corrected estimates is obtained by bootstrapping the design matrix with 100 replications.

Table 7 reports the QR estimates of the coefficient on the Female indicator for a few relevant percentiles of the PP distribution. A clear "glass ceiling" pattern emerges with the gap evolving from 20 log-points at the bottom deciles to $43 \log$ points at the top of the distribution. 


\section{[Table 7 about here]}

\section{Reconciling the evidence with the alternative hypotheses}

So far, the main findings regarding the PP gender gaps for our sample of workers in Spain, once we adjust for individual and job caracteristics, and for non-random sample selection (labeled as "similar men and women" in the sequel), can be summarized as follows:

1. Female incidence in PP schemes is clearly smaller than male's when comparing similar men and women.

2. The adjusted gender gap in PP compensation for similar men and women who work in the same firm and occupation is around $2 / 3$ of the total raw gap. Further, the adjusted gender gap within occupations is about the same as the one observed across occupations.

3. There is a clear glass-ceiling component in the gender gap in PP when we compare similar men and women working in the same firm and occupation.

In view of this evidence, some of the potential explanations described in the Introduction may be ruled out as possible determinants of the PP gender gap in Spain. In particular:

- $\quad$ The lower incidence of women in PP schemes goes against the hypothesis stating that, under the competitive labour market paradigm, equally productive men and women should exhibit no significant differences regarding participation in jobs offering PP compensation and that, when females anticipate non-competitive features in non PP jobs, they should be more prevalent in PP jobs.

- $\quad$ The fact that the adjusted gender gap within occupations is nearly the same as across occupations, and that its remains at almost 30 log-points (two-thirds to the total gap) within the same firm and occupation, rules out occupational segregation in its different formats as a valid explanation of the sizeable gender gaps in PP.

This leaves us with two remaining explanations for our findings, one based on supply and another on demand considerations. On the one hand, from the supply side, women may have lower preferences than men as regards to the pecuniary-content of the PP component, or they may exert less effort at the workplace for housework and/or other family reasons. Both hypotheses would lead to a large gender gap in the PP component between equally skilled men and women working in almost identical jobs. 
On the other hand, from the demand side, the observed gender gaps may be a result of discrimination from employers with monopsonistic power who find it optimal to pay women less in terms of PP than equally productive men. These two different explanations have radically different implications in terms of gender policies, but identifying which is the more appropriate one is quite complicated.

Although it is not possible to test for gender differences in preferences regarding PP with the information available in our dataset, there is a feature that does not seem to support this hypothesis, namely the observed glass-ceiling pattern of these gaps. In principle, one would rather think that these differences lead to uniform gaps along the distribution, unless we assume that female preferences with respect to the pecuniary components of PP decrease with qualification and skills which, to our knowledge, does not find any empirical support.

As regards the possibility that women may exert lower effort at the workplace because of their higher involvement in housework, we can provide some stronger evidence against it, despite lacking family information in our dataset. Indeed, the fact that our sample only considers full-time workers, that the PP component is measured on an hourly basis and that we control for age, education and tenure - all related to productivity- as well as that the number of overtime hours reported are similar for men and women who receive PP (60.2 and 59.8 per year, respectively)- make us think that gender differences in effort do not play an important role in explaining the PP gender gap. Moreover, an indirect test for gender differences in effort can be performed by checking whether the proportion that PP represents over the total hourly wage is lower for similar men and women in the same jobs and occupations. The insight is simply that higher effort should lead to a larger proportion of PP in the total wage. As mentioned above, on average, these proportions are $9 \%$ for men and $7.2 \%$ for women. Though not reported for brevity, we have run a similar mincerian regression to the one in column (5) of Table 6, where the dependent variable is the logit transformation of the abovementioned proportion. ${ }^{6}$ We obtain that the Female indicator explains one-fourth $(0.45$ pp.) of the 1.8 p.p. gap (=9.0-7.2) in the above-mentioned proportions. Thus, although there is some evidence that differences in effort may play a role in explaining the gap, the estimated contribution is not sufficiently large to consider this hypothesis as the key explanation.

\footnotetext{
6 The logit transformation, $\ln (R / 1-R) \in(-\infty,+\infty)$, achieves consistency with the support of the distribution of the error tem in the regression, where $R \in(0,1)$ is the proportion of PP in the total hourly wage. Denoting by $b$ the estimated coefficient in the regression, then the effect of the Female dummy, $D$, on $R$ becomes $\delta R / \delta D=b R(1-R)$.
} 
Furthermore, the glass-ceiling pattern found for the gender gap in PP is not easy to reconcile with the "gender difference in effort" hypothesis since it is hard to provide plausible reasons for why gender differences in effort should be larger among the highest qualified workers. If anything, we should expect the opposite pattern, namely that these differences should be higher for low-qualified workers, as the opportunity costs of exerting lower effort for these female workers are likely to be lower.

In view of these considerations, the only hypothesis which seems to be consistent our empirical findings would be one involving some sort of discrimination from the employer's side. In particular, assuming that female labour mobility is lower than male's, employers would exploit their monopsonistic power by paying less PP to women than to their male counterparts working in the same firm and occupation. Furthermore, since the rate of exploitation under monopsony (i.e., the relative difference between marginal revenue and wage) is the inverse of the elasticity of labour supply (Alshenfelter et al. 2010) and it is likely that this elasticity is lower for more skilled workers (see Hirsch et al., 2010), ${ }^{7}$ monopsonistic power by firms would also imply that the PP gender gap increases throughout the PP distribution, in line with our finding of a glass-ceiling pattern.

Obviously, the conclusion reached above is just a conjecture since the lack of family information in our dataset prevents us from formally testing whether family conditions affecting women (e.g., being married or having children/elderly dependents in charge) play a major role in explaining the findings. It is high in our research agenda to merge ESS 06 with other datasets where this information is available.

\section{Concluding remarks}

In this paper we have used a large cross-sectional dataset for workers in Spain to examine whether the gender gap in PP differs from the corresponding gaps in the other components of wage compensation. We have found evidence that PP responds more to workers' performance and that women receiving PP have several observable characteristics which are better than men 's (e.g., educational attainment). Yet, our main result is that the gender gap in PP is much higher, both in raw terms and adjusted for observable characteristics and for segregation into different firms and occupations, than the gap in non-PP compensation, and that there are clear signs of a "glass ceiling" effect

\footnotetext{
7 For example, this would be the case if the income effect is strong at higher wages, likely to be related to high skills, and therefore the labour supply schedule becomes either vertical or even backward bending.
} 
(higher gaps and lower female participation of women in the upper parts of the PP distribution). We have argued that, in principle, these findings taken together cannot be reconciled with hypotheses such as occupational segregation, lower female effort at the workplace, the competitive labour market paradigm, or gender differences in attitudes toward competition. Our preferred explanation for these findings relies mostly on some sort of monopsonistic discrimination by employers against women due to their lower lower mobility or lack of potential job offers. Furthermore, the monopsonistic explanation for gender gaps in PP would be consistent with the glass-ceiling pattern found for the PP gender gaps since the rate of exploitation under monopsony is the inverse of the elasticity of labour supply and this elasticity tend to be lower for more skilled workers. 


\section{References}

Booth, A., Francesconi, M \& J. Frank (2003), "A sticky floors model of promotion, pay and gender", European Economic Review, 47, 295-322.

Buchinsky, M. (2001), "Quantile regression with sample selection. Estimating women's returns to education in the U.S." Empirical Economics, 26, 87-113.

Calmfors., L. \& J. Drifill (1988), “Bargaining structure, corporatism and macroeconomic performance", Economic Policy 3, 13-61.

Chauvin, K. \& R. Ash (1994), "Gender earnings differentials in total pay, base pay, and contingent pay". Industrial and Labor Relations Review, 47, 634-649

De la Rica, S., Dolado, J. \& R. Vegas (2010),"Performance pay and the gender wage gap. Evidence from Spain", CEPR DP 7936.

Dolado, J., García-Peñalosa, C. \& S. de la Rica (2012), "On gender gaps and selffulfilling expectations: Alternative implications of paid-for-training", forthcoming in Economic Inquiry.

Dolado, J., Jimeno, J. \& F. Felgueroso (1997), "Minimum wages, collective bargaining and wage dispersion: The Spanish case", European Economic Review, 41, 713-725.

Dohmen, T. \& A. Falk (2009), "Performance pay and multi-dimensional sorting productivity, preferences and gender", forthcoming in American Economic Review.

Gneezy, U., Nierderle, M. \& A. Rustichini (2003), “Performance in competitive environments: Gender Differences", Quarterly Journal of Economics, 118, 1049-1076.

Hirsch , B., Schank, T. \& C. Schnabel (2010), "Differences in labor supply to monopsonistic firms and the gender pay gap: An empirical analysis using linked employer-employee data from Germany", Journal of Labor Economics 28, 291-330

Lavy, V. (2009), "Performance pay and teachers' effort, productivity and grading ethics", American Economic Review, 99, 1979-2011.

Lavy, V. (2011), " Gender differences in market competitiveness in a real workplace. Evidence from performance-based pay tournament among teachers", Hebrew University and Royal Holloway UL, mimeo.

Lazear, E. \& S. Rosen (1981), “"Rank-order tournaments as optimum labor contracts," Journal of Political Economy 89, 841-864.

Lazear, E. (2000): “Performance Pay and Productivity," American Economic Review, 90, 1346-1362. 
Lemieux, T. , MacLeod, B. \& D. Parent, (2009), "Performance Pay and Wage Inequality", Quarterly Journal of Economics, 124, 1-49.

Manning, A. (2003), "Monopsony in Motion: Imperfect Competition in Labor Markets", Princeton University Press.

Manning, A. \& F. Saidi (2010)), “Understanding the Gender Pay Gap: What's Competition Got to Do with It?", Industrial and Labor Relations Review, 63, 681-698.

Mincer, J. \& S. Polacheck (1977), “Women's earnings re-examined”, Journal of Human Resources, 13 , 118-134.

Nierderle, M. \& L. Vesterlund (2007), "Do women shy away from competition ?", Quarterly Journal of Economics, 122, 1067-1101. 


\section{$\underline{\text { List of Tables }}$}

Table 1 - Sample characteristics (Full-time workers between 18-65 years of age)

\begin{tabular}{|c|c|c|}
\hline Variables & Women $(65,233)$ & Men $(129,930)$ \\
\hline & Mean & Mean \\
\hline \multicolumn{3}{|l|}{ Individual Characteristics } \\
\hline \multicolumn{3}{|l|}{$\overline{\text { Education }}$} \\
\hline Primary or less & 0.176 & 0.275 \\
\hline Secondary & 0.508 & 0.545 \\
\hline University & 0.316 & 0.180 \\
\hline \multicolumn{3}{|l|}{ Age } \\
\hline Less 30 years & 0.257 & 0.200 \\
\hline $31-40$ & 0.354 & 0.323 \\
\hline $41-50$ & 0.245 & 0.265 \\
\hline$>50$ & 0.143 & 0.212 \\
\hline Tenure (years) & 7.410 & 8.867 \\
\hline Permanent Contract & 0.727 & 0.768 \\
\hline \multicolumn{3}{|l|}{ Wages } \\
\hline Total Hourly Wage (logs) & 2.185 & 2.391 \\
\hline \multicolumn{3}{|c|}{ Performance Pay (only PP workers) } \\
\hline$\%$ PP job & 0.177 & 0.194 \\
\hline Total Hourly Wage (logs) & 2.508 & 2.764 \\
\hline Fixed Hourly Wage (logs) & 2.430 & 2.664 \\
\hline PP Hourly Wage (logs) & -0.663 & -0.203 \\
\hline \multicolumn{3}{|l|}{ Firm Characteristics } \\
\hline \multicolumn{3}{|l|}{ Size } \\
\hline$<50$ workers & 0.339 & 0.403 \\
\hline 51-200 workers & 0.265 & 0.288 \\
\hline$>200$ workers & 0.396 & 0.309 \\
\hline Firm Bargaining Agreement. & 0.133 & 0.198 \\
\hline Exporting firms & 0.183 & 0.194 \\
\hline
\end{tabular}

Source: EES (2006)

Note: The null of equal means across genders is always rejected. 
Table 2a: Characteristics of workers and firms by type of job and gender

\begin{tabular}{|c|c|c|c|c|}
\hline & \multicolumn{2}{|l|}{ PP sample } & \multicolumn{2}{|c|}{ Non-PP sample } \\
\hline & $\begin{array}{c}\text { Women } \\
\text { (14.789 obs.) }\end{array}$ & $\begin{array}{c}\text { Men } \\
\text { (29.460 obs.) }\end{array}$ & $\begin{array}{c}\text { Women } \\
\text { (50.444 obs.) }\end{array}$ & $\begin{array}{c}\text { Men } \\
(100.470 \text { obs. })\end{array}$ \\
\hline Variables & Mean & Mean & Mean & Mean \\
\hline \multicolumn{5}{|l|}{ Education } \\
\hline Primary or less & 0.107 & 0.178 & 0.196 & 0.304 \\
\hline Secondary & 0.494 & 0.545 & 0.512 & 0.545 \\
\hline University & 0.399 & 0.277 & 0.292 & 0.151 \\
\hline \multicolumn{5}{|l|}{ Age } \\
\hline Less 30 years & 0.204 & 0.149 & 0.273 & 0.215 \\
\hline $31-40$ & 0.313 & 0.385 & 0.346 & 0.325 \\
\hline $41-50$ & 0.265 & 0.294 & 0.239 & 0.257 \\
\hline$>50$ & 0.150 & 0.244 & 0.141 & 0.203 \\
\hline Tenure (years) & 9.281 & 12.037 & 6.861 & 7.938 \\
\hline Permanent Contract & 0.814 & 0.862 & 0.741 & 0.741 \\
\hline \multicolumn{5}{|l|}{ Firm Characteristics } \\
\hline \multicolumn{5}{|l|}{ Size } \\
\hline$<50$ workers & 0.201 & 0.235 & 0.380 & 0.452 \\
\hline 51-200 workers & 0.239 & 0.297 & 0.272 & 0.285 \\
\hline >200 workers & 0.560 & 0.467 & 0.348 & 0.262 \\
\hline \multicolumn{5}{|c|}{ Collective Bargaining (ref: Industry level) } \\
\hline Firm Collective Bargaining & 0.193 & 0.288 & 0.154 & 0.167 \\
\hline \multicolumn{5}{|c|}{ Firm Market (ref: International Market) } \\
\hline Local or Nat. Market & 0.181 & 0.239 & 0.135 & 0.153 \\
\hline
\end{tabular}

Source: EES (2006)

Note: The null of equal means across is always rejected. 
Table 2b: Incidence of PP by industry and occupation

\begin{tabular}{lccc}
\hline & Mean & Std. Dev. & No. Obs. \\
\hline Industries & & & \\
Financial Intermediation & 0.598 & 0.49 & 10475 \\
Energy & 0.324 & 0.468 & 4627 \\
Transportation & 0.324 & 0.468 & 12710 \\
Health & 0.287 & 0.452 & 14178 \\
Retail trade & 0.241 & 0.427 & 17131 \\
Manufactures & 0.205 & 0.404 & 74332 \\
Real State and Res. Serv. & 0.194 & 0.395 & 16342 \\
Mine \& Extractive Ind. & 0.188 & 0.391 & 2919 \\
Other Services & 0.146 & 0.353 & 9040 \\
Construction & 0.127 & 0.333 & 17096 \\
Hotels and Restaurants & 0.123 & 0.328 & 8315 \\
Education & 0.092 & 0.289 & 7998 \\
Occupations & & & \\
Managers & 0.497 & 0.5 & 6190 \\
Technicians & 0.326 & 0.469 & 30184 \\
Professionals & 0.288 & 0.453 & 20295 \\
Clerks & 0.257 & 0.437 & 24761 \\
Personal Services & 0.196 & 0.397 & 17528 \\
Operators and Assemblers & 0.18 & 0.384 & 34822 \\
Craftsmen & 0.169 & 0.375 & 37918 \\
Agriculture and Fisheries & 0.146 & 0.353 & 542 \\
Laborers, non-qualified operators & 0.127 & 0.333 & 22923 \\
\hline Source EES (2006) & & &
\end{tabular}

Source: EES (2006) 
Table 2c: Share of women throughout PP distribution

$\%$ Women in percentiles

\begin{tabular}{|c|c|}
\hline [P1th_P10th] & $32.7 \%$ \\
\hline [P11th_P25th] & $32.4 \%$ \\
\hline [P26th-P50th] & $31.6 \%$ \\
\hline [P51th_P75th] & $25.6 \%$ \\
\hline [P76th_P90th] & $19.8 \%$ \\
\hline [P91th_P95th] & $14.9 \%$ \\
\hline [P95th_P100th] & $13.7 \%$ \\
\hline
\end{tabular}

Source: EES (2006)

Table 3: Hourly wages in PP and non-PP samples

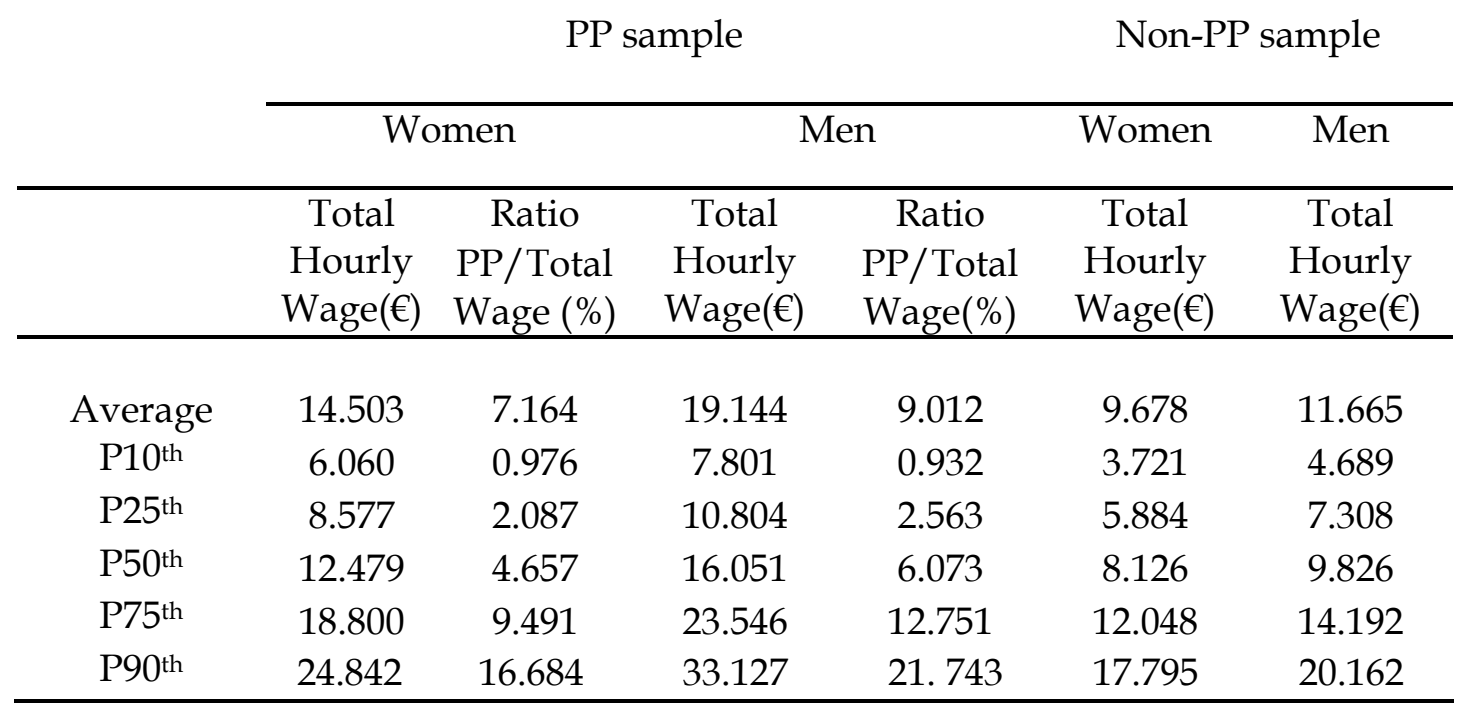

Source: EES (2006) 
Table 4: Log hourly wage regressions

Dependent Variable: (Log) Total Hourly Wage

\begin{tabular}{|c|c|c|c|}
\hline & $\begin{array}{c}(1) \\
\text { PP sample }\end{array}$ & $\begin{array}{c}(2) \\
\text { Non-PP sample }\end{array}$ & $\begin{array}{c}\text { (3) } \\
\text { Pooled sample }\end{array}$ \\
\hline PP Indicator & & & $\begin{array}{c}0.208^{* * *} \\
(0.009)\end{array}$ \\
\hline Female & $\begin{array}{c}-0.223^{* * *} \\
(0.004)\end{array}$ & $\begin{array}{c}-0.212^{* * *} \\
(0.003)\end{array}$ & $\begin{array}{c}-0.219^{* * *} \\
(0.004)\end{array}$ \\
\hline Age 30-39 (ref.:<30) & $\begin{array}{c}0.167^{* * *} \\
(0.006)\end{array}$ & $\begin{array}{c}0.098^{* * *} \\
(0.003)\end{array}$ & $\begin{array}{c}0.095^{* * *} \\
(0.004)\end{array}$ \\
\hline Age $41-49$ & $\begin{array}{c}0.218^{* * *} \\
(0.007)\end{array}$ & $\begin{array}{c}0.116^{* * *} \\
(0.004)\end{array}$ & $\begin{array}{l}0.114^{* * *} \\
(0.004)\end{array}$ \\
\hline Age 50-59 & $\begin{array}{c}0.235^{* * *} \\
(0.008)\end{array}$ & $\begin{array}{c}0.161^{* * *} \\
(0.004)\end{array}$ & $\begin{array}{c}0.161^{* * *} \\
(0.005)\end{array}$ \\
\hline Age $>60$ & $\begin{array}{c}0.262^{* * *} \\
(0.014)\end{array}$ & $\begin{array}{c}0.155^{* * *} \\
(0.007)\end{array}$ & $\begin{array}{c}0.158^{* * *} \\
(0.008)\end{array}$ \\
\hline $\begin{array}{l}\text { College } \\
\text { (ref: Primary) }\end{array}$ & $\begin{array}{c}0.277^{* * *} \\
(0.007)\end{array}$ & $\begin{array}{c}0.223^{* * *} \\
(0.005)\end{array}$ & $\begin{array}{c}0.215^{* * *} \\
(0.004)\end{array}$ \\
\hline Secondary & $\begin{array}{c}0.077^{* * *} \\
(0.006)\end{array}$ & $\begin{array}{c}0.063^{* * *} \\
(0.003)\end{array}$ & $\begin{array}{c}0.060^{* * *} \\
(0.003)\end{array}$ \\
\hline Tenure & $\begin{array}{c}0.044^{* * *} \\
(0.001)\end{array}$ & $\begin{array}{c}0.042^{* * *} \\
(0.000)\end{array}$ & $\begin{array}{c}0.043^{* * *} \\
(0.000)\end{array}$ \\
\hline Tenure sq. & $\begin{array}{c}-0.001^{* * *} \\
(0.001)\end{array}$ & $\begin{array}{c}-0.001^{* * *} \\
(0.000)\end{array}$ & $\begin{array}{c}-0.001^{* * *} \\
(0.000)\end{array}$ \\
\hline Permanent Contract & $\begin{array}{c}0.282^{* * *} \\
(0.006)\end{array}$ & $\begin{array}{c}0.313^{* * *} \\
(0.003)\end{array}$ & $\begin{array}{c}0.312^{* * *} \\
(0.003)\end{array}$ \\
\hline $\begin{array}{l}\text { Firm Size: 50-199 } \\
\text { (Ref: <50) }\end{array}$ & $\begin{array}{c}0.067^{* * *} \\
(0.005)\end{array}$ & $\begin{array}{c}0.095^{\star * *} \\
(0.003)\end{array}$ & $\begin{array}{c}0.094^{* * *} \\
(0.003)\end{array}$ \\
\hline Firm Size: >199 & $\begin{array}{c}0.118^{* * *} \\
(0.005)\end{array}$ & $\begin{array}{l}0.166^{* * *} \\
(0.003)\end{array}$ & $\begin{array}{c}0.164^{* * *} \\
(0.003)\end{array}$ \\
\hline Firm Agreement & $\begin{array}{c}0.011 \\
(0.012)\end{array}$ & $\begin{array}{l}0.014^{*} \\
(0.008)\end{array}$ & $\begin{array}{c}0.013 \\
(0.008)\end{array}$ \\
\hline Export market & $\begin{array}{c}0.027^{* * *} \\
(0.005)\end{array}$ & $\begin{array}{c}0.035^{* * *} \\
(0.003)\end{array}$ & $\begin{array}{c}0.045^{* * *} \\
(0.003)\end{array}$ \\
\hline Interactions with PP & & & \\
\hline Female*PP & & & $\begin{array}{l}-0.023 \\
(0.005)\end{array}$ \\
\hline Age $30-39 * P P($ ref:<30) & & & $\begin{array}{c}0.059^{* * *} \\
(0.007)\end{array}$ \\
\hline Age $41-49^{*} \mathrm{PP}$ & & & $\begin{array}{l}0.103^{* * *} \\
(0.008)\end{array}$ \\
\hline Age $50-59 * P P$ & & & $\begin{array}{c}0.089^{* * *} \\
(0.010)\end{array}$ \\
\hline Age $>60 * \mathrm{PP}$ & & & $\begin{array}{c}0.127^{* * *} \\
(0.016)\end{array}$ \\
\hline $\begin{array}{l}\text { College*PP } \\
\text { (ref: Primary) }\end{array}$ & & & $\begin{array}{c}0.100^{* * *} \\
(0.007)\end{array}$ \\
\hline
\end{tabular}


Secondary*PP

Tenure*PP

$(0.006)$

$0.011^{* *}$

$(0.005)$

Permanent Contract*PP

$-0.025^{* * *}$

$(0.007)$

Firm Size: $(r e f<50)$

$-0.027^{* * *}$

50-199*PP

(0.006)

Firm Size: >199PP

$-0.042^{* * *}$

$(0.006)$

Firm Agreement*PP

$-0.006$

$(0.005)$

Export. Firm *PP

$-0.014^{* * *}$

(0.006)

No. Obs.

$\mathrm{R}$ sq.

44249

150914

195163

Note: s.e's. in parentheses. Estimations also control for industry, regional dummies and occupational dummies). 
Table 5: Probit estimation

Dependent Variable: Receiving Performance Pay (1/0)

\begin{tabular}{lc} 
Female & $-0.047^{* * *}$ \\
Age 30-39 (ref:<30) & $(0.008)$ \\
& $0.052^{* * *}$ \\
Age 40-49 & $(0.010)$ \\
& $0.032^{* * *}$ \\
Age 50-59 & $(0.011)$ \\
& 0.015 \\
Age >60 & $(0.013)$ \\
& $-0.076^{* * *}$ \\
University & $(0.023)$ \\
(ref: Primary) & $0.260^{* * *}$ \\
Secondary & $(0.013)$ \\
& $0.164^{* * *}$ \\
Tenure & $(0.009)$ \\
& $0.030^{* * *}$ \\
Tenure square & $(0.001)$ \\
& $-0.001^{* * *}$ \\
Permanent Contract & $(0.000)$ \\
& $0.037^{* * *}$ \\
Firm Size: 50-199 & $(0.010)$ \\
(Ref: <50) & $0.295^{* * *}$ \\
Firm Size: $>199$ & $(0.009)$ \\
& $0.485^{* * *}$ \\
Firm Collective Agreement & $(0.008)$ \\
& $0.096^{* *}$ \\
Exporting firm & $(0.009)$ \\
& $0.122^{* * *}$ \\
Pseudo R & $(0.009)$ \\
\hline & 195163 \\
\hline & 0.111 \\
\hline
\end{tabular}


Table 6: Estimates of log. PP hourly wage equation

Dependent Variable: log PP hourly wage component

\begin{tabular}{|c|c|c|c|c|c|}
\hline & (OLS) & (IV) & (WO) & $(\mathrm{WF})$ & (WFO) \\
\hline Female & $\begin{array}{c}-0.407^{* * *} \\
(0.014)\end{array}$ & $\begin{array}{c}-0.453^{* * *} \\
(0.015)\end{array}$ & $\begin{array}{c}-0.432^{* * *} \\
(0.016)\end{array}$ & $\begin{array}{c}-0.361^{* * *} \\
(0.015)\end{array}$ & $\begin{array}{c}-0.298^{* * *} \\
(0.019)\end{array}$ \\
\hline$\%$ Fem. rate in Firm & & & $\begin{array}{c}-0.103^{* * *} \\
(0.033)\end{array}$ & & \\
\hline$\%$ Fem. rate in Occupation & & & & $\begin{array}{c}-0.200^{* * *} \\
(0.037)\end{array}$ & \\
\hline \% Fem. rate in Firm \& Occ. & & & & & $\begin{array}{c}-0.295^{* * *} \\
(0.028)\end{array}$ \\
\hline Inv. Mills Ratio & & $\begin{array}{c}1.628^{* * *} \\
(0.170)\end{array}$ & $\begin{array}{c}1.693^{* * *} \\
(0.170)\end{array}$ & $\begin{array}{c}1.690^{* * *} \\
(0.198)\end{array}$ & $\begin{array}{c}1.984^{* * *} \\
(0.141)\end{array}$ \\
\hline Personal Characteristics & & Yes & Yes & Yes & Yes \\
\hline Job Characteristics & & Yes & Yes & Yes & Yes \\
\hline No. obs. & & 44,249 & 44,249 & 44,249 & 44,249 \\
\hline R-sq. & & 0.160 & 0.165 & 0.165 & 0.167 \\
\hline
\end{tabular}

Note: s.e's. in parentheses. Coefficients in (1) are derived from an OLS regression over the overall sample of workers. Coefficients in (2) are derived from Heckman estimation, performed to correct for selection into PP jobs. Coefficients in (3) to (5) also control for the femaleness rate within firm, within occupations and within firm and occupations, respectively. Inverse Mills ratio derived from estimates in (2) are included in the three last columns as an additional covariate to correct for selectivity. 
Table 7: Adjusted Gender Gaps in PP - Quantile Regressions (with selection correction and with firm and occupation fixed effects)

Dependent Variable: Log PP Hourly Wage

\begin{tabular}{cccccc}
\hline & $(1)$ & $(2)$ & $(3)$ & $(4)$ & $(5)$ \\
& P10th & P25th & P50th & P75th & P90th \\
\hline Female (WFO) & $-0.226^{* * *}$ & $-0.281^{* * *}$ & $-0.318^{* * *}$ & $-0.357^{* * *}$ & $-0.366^{* * *}$ \\
& $(0.034)$ & $(0.023)$ & $(0.022)$ & $(0.026)$ & $(0.027)$ \\
\hline
\end{tabular}

Note: s.e's. in parentheses. Estimations also control for the whole set of covariates in Table 6. 


\section{ÚLTIMOS DOCUMENTOS DE TRABAJO}

2013-14: "Gender Gaps in Performance Pay: New Evidence from Spain", Sara de la Rica, Juan J. Dolado y Raquel Vegas.

2013-13: "On Gender Gaps and Self-Fulfilling Expectation: Alternative Implications of Paid-For Training", Juan J. Dolado, Cecilia García-Peñalosa y Sara de la Rica.

2013-12: "Financial incentives, health and retirement in Spain", Pilar García-Gómez, Sergi Jiménez-Martín y Judit Vall Castelló.

2013-11: "Gender quotas and the quality of politicians", Audinga Baltrunaite, Piera Bello, Alessandra Casarico y Paola Profeta.

2013-10: "Brechas de Género en los Resultados de PISA :El Impacto de las Normas Sociales y la Transmisión Intergeneracional de las Actitudes de Género", Sara de la Rica y Ainara González de San Román.

2013-09: "¿Cómo escogen los padres la escuela de sus hijos? Teoría y evidencia para España", Caterina Calsamiglia, Maia Güell.

2013-08: "Evaluación de un programa de educación bilingüe en España: El impacto más allá del aprendizaje del idioma extranjero", Brindusa Anghel, Antonio Cabrales y Jesús M. Carro.

2013-07: "Publicación de los resultados de las pruebas estandarizadas externas: ¿Tiene ello un efecto sobre los resultados escolares?", Brindusa Anghel, Antonio Cabrales, Jorge Sainz e Ismael Sanz.

2013-06: "DYPES: A Microsimulation model for the Spanish retirement pension system", F. J. FernándezDíaz, C. Patxot y G. Souto.

2013-05: "Vertical differentiation, schedule delay and entry deterrence: Low cost vs. full service airlines", Jorge Validoa, M. Pilar Socorroa y Francesca Medda.

2013-04: "Dropout Trends and Educational Reforms: The Role of the LOGSE in Spain", Florentino Felgueroso, María Gutiérrez-Domènech y Sergi Jiménez-Martín.

2013-03: "Understanding Different Migrant Selection Patterns in Rural and Urban Mexico", Simone Bertoli, Herbert Brücker y Jesús Fernández-Huertas Moraga.

2013-02: "Understanding Different Migrant Selection Patterns in Rural and Urban Mexico", Jesús Fernández-Huertas Moraga.

2013-01: "Publicizing the results of standardized external tests: Does it have an effect on school outcomes?, Brindusa Anghel, Antonio Cabrales, Jorge Sainz y Ismael Sanz.

2012-12: "Visa Policies, Networks and the Cliff at the Border", Simone Bertoli, Jesús Fernández-Huertas Moraga.

2012-11: "Intergenerational and Socioeconomic Gradients of Child Obesity", Joan Costa-Fonta y Joan Gil.

2012-10: "Subsidies for resident passengers in air transport markets", Jorge Valido, M. Pilar Socorro, Aday Hernández y Ofelia Betancor.

2012-09: "Dual Labour Markets and the Tenure Distribution: Reducing Severance Pay or Introducing a Single Contract?", J. Ignacio García Pérez y Victoria Osuna.

2012-08: "The Influence of BMI, Obesity and Overweight on Medical Costs: A Panel Data Approach", Toni Mora, Joan Gil y Antoni Sicras-Mainar.

2012-07: "Strategic behavior in regressions: an experimental", Javier Perote, Juan Perote-Peña y Marc Vorsatz.

2012-06: "Access pricing, infrastructure investment and intermodal competition", Ginés de Rus y M. Pilar Socorro.

2012-05: "Trade-offs between environmental regulation and market competition: airlines, emission trading systems and entry deterrence", Cristina Barbot, Ofelia Betancor, M. Pilar Socorro y M. Fernanda Viecens.

2012-04: "Labor Income and the Design of Default Portfolios in Mandatory Pension Systems: An Application to Chile", A. Sánchez Martín, S. Jiménez Martín, D. Robalino y F. Todeschini.

2012-03: "Spain 2011 Pension Reform", J. Ignacio Conde-Ruiz y Clara I. Gonzalez.

2012-02: "Study Time and Scholarly Achievement in PISA", Zöe Kuehn y Pedro Landeras.

2012-01: "Reforming an Insider-Outsider Labor Market: The Spanish Experience", Samuel Bentolila, Juan J. Dolado y Juan F. Jimeno.

2011-13: "Infrastructure investment and incentives with supranational funding", Ginés de Rus y M. Pilar Socorro.

2011-12: "The BCA of HSR. Should the Government Invest in High Speed Rail Infrastructure?", Ginés de Rus.

2011-11: "La rentabilidad privada y fiscal de la educación en España y sus regiones", Angel de la Fuente y Juan Francisco Jimeno.

2011-10: "Tradable Immigration Quotas", Jesús Fernández-Huertas Moraga y Hillel Rapoport.

2011-09: "The Effects of Employment Uncertainty and Wealth Shocks on the Labor Supply and Claiming Behavior of Older American Workers", Hugo Benítez-Silva, J. Ignacio García-Pérez y Sergi Jiménez-Martín.

2011-08: "The Effect of Public Sector Employment on Women's Labour Martket Outcomes", Brindusa Anghel, Sara de la Rica y Juan J. Dolado. 